\title{
Investigation of Shear Stiffness of Spine Bracing Systems in Selective Pallet Racks
}

\author{
Bo Cheng ${ }^{*}$ and Zhenyu $\mathrm{Wu}$
}

School of Civil Engineering, Harbin Institute of Technology, Harbin, 150090, P.R. China

\begin{abstract}
This paper presents a general analysis on the shear stiffness of spine bracing systems of selective storage racks in the down-aisle direction. Unlike the architectural steel structure, the bearing capacity of bracing connection in the spine bracing systems of steel rack structure is weaker than that of bracing members. Firstly, destructive tests of spine bracing connection in single entry racks have been conducted. In the tests, a portion of column web around bolt holes is damaged due to the pull force of connecting bolts. Based on the experimental results, the finite element shell model of tested bracing connection is developed, and the emulation method is also used to analyze the deformation behavior of spine bracing connections in double entry racks. The calculating results indicate that, with better mechanical behavior and less local deformation, the tensile stiffness of bracing connection in double entry racks is much larger than that of bracing connection in single entry racks. From the trial calculation, the simplified models using elastic plastic beam elements are proposed. These simplified models can be adopted in the overall deformation analysis of selective pallet racks subjected to horizontal loading. Through the comparative analysis of single entry racks and double entry racks which have four bays and eight floors, the lateral deformation of double entry racks is considerably less than that of single entry racks, showing the large different effect of spine bracing systems on two rack lateral behavior.
\end{abstract}

Keywords: Bracing bracket connection, local deformation, selective pallet racks, shear stiffness, spine bracings.

\section{INTRODUCTION}

Storage rack is a load bearing system designed to store goods on pallets. There are many varieties of storage racks in the market, and besides, selective pallet rack is the most common type in use today. The configuration of a typical selective rack structure with bracings is shown in Fig. (1) [1]. The pallet load is placed on horizontal beams by forklift or handling device. Column frame, which is composed of two perforated columns and their bracing members, transmits the goods gravity load to the ground.

As shown in Fig. (1), selective pallet racks generally fall into two categories: single entry rack and double entry rack. Fig. (2) shows an application example of spine bracing system in a single entry rack. In general, spine bracing system includes two components: diagonal bracing member and short bracing bracket. In order to avoid the collision of spine bracing members and goods pallets which are supported by the beams, spine bracing members cannot be set in the same vertical plane with rack beams, and there should be some space between bracing members and beams. Using a short bracing bracket, the spine bracing member is fixed on the web of rack column. For the special construction details of bracing bracket connection which links spine bracing and rack column, the local deformation inevitably occurs in the bracing connection.

*Address correspondence to this author at the School of Civil Engineering, Harbin Institute of Technology, Huanghe Road, Nangang District, Harbin, Heilongjiang, 150090, P.R. China; Tel: +86 13845078064; +86 451 86283197; Fax:+86451 86282704; E-mail: chengbo198508@126.com
The bearing capacity of bracing connection is lower than that of bracing member, but this situation clearly violates the architectural steel structure design principle "strong-joint and weak-member". The local deformation in connection can seriously weaken the shear stiffness of spine bracing system, especially for single entry racks. In single entry racks, spine bracing is installed at one side of rack, thus cargo pallet is loaded and unloaded from the other side of racks. Due to the large slenderness ratio of spine bracing members, the bracing members cannot withstand pressure and can only support against tension.
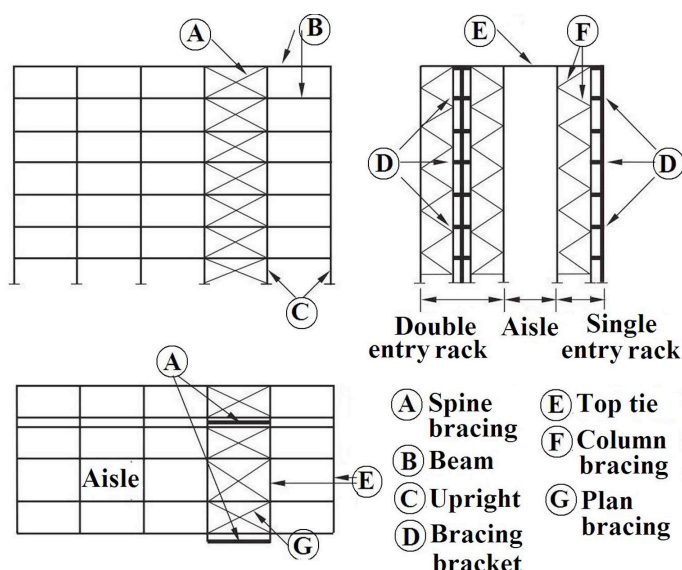

entry rack entry rack

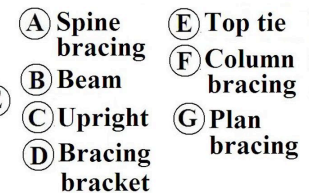

Fig. (1). Configuration of a braced storage pallet rack structure [1].

This paper presented four static destructive tests on spine bracing connection of single entry racks for the purpose of evaluating the tensile stiffness and ultimate bearing capacity 
of bracing connections. Moreover, finite element model which can reasonably simulate the behavior of tested connections is proposed. Using the similar simulation method, the spine bracing connection in double entry racks is also simulated. Finally, for the sake of comparing the effect of spine bracing on the lateral behavior of single entry racks and double entry racks in the down-aisle direction, the lateral deformation of high racks is calculated.

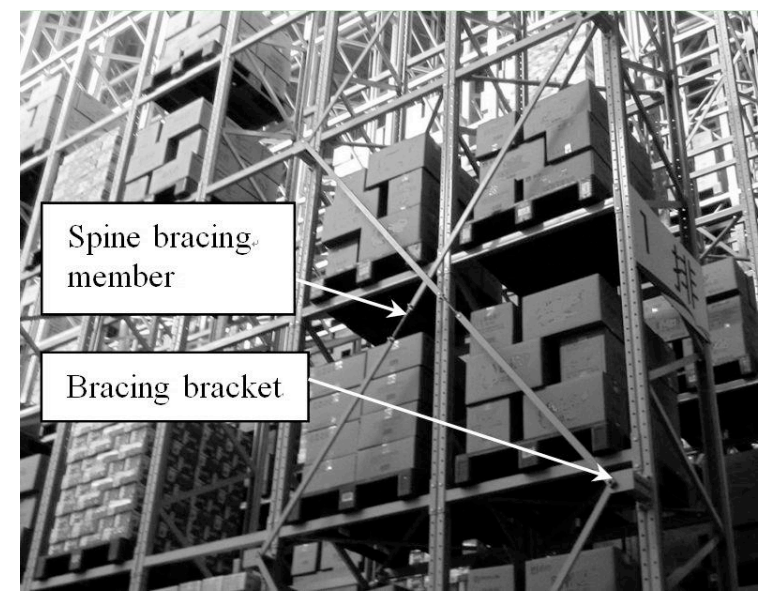

Fig. (2). Vertical spine bracing structure of a single entry rack.

\section{CONNECTION TEST IN SINGLE ENTRY RACK}

The vertical spine bracing connection in single entry racks has been tested in this section. The configuration of tested connection is shown in Fig. (3). In addition to bracing bracket and its two end plates, tested connection specimen also includes a short column and a short bracing member. Both ends and flanges of horizontal short column are welded on a steel plate, which is fixed on test reaction frame. The far end of bracing member, through a force transducer, is connected to a hydraulic jack that exerts a pulling force. Two LVDTs (Linear Variable Displacement Transducers) are used to monitor the horizontal displacement of the far end of the short bracing member.

Rack columns in the experimental bracing connections have two kinds of thickness. According to different column thickness, the columns are divided into Column 1 and Column 2. However, two column cross section forms are the same, and the size of cross section is $100 \mathrm{~mm} \times 70 \mathrm{~mm}$. Bracing bracket and bracing member are light gauge $\mathrm{C}$-section members with the size $100 \mathrm{~mm} \times 50 \mathrm{~mm}$ and $50 \mathrm{~mm} \times 30 \mathrm{~mm}$ respectively. Among the components of tested bracing connection, column web and bracing bracket generate the large deformation, thus material properties of the two components were tested through the material tensile test. The results of the tensile test are listed in Table 1. This table also lists the measured plate thickness of connection components.

Fig. (4) shows the failure phenomena of tested bracing bracket connection. It should be noted that some part of white coating of short horizontal column changes into black because of the welding. A portion of column web around bolt holes is damaged due to the pull force of connecting bolts. Meanwhile there is the large torsional deformation for bracing bracket. Experimental tensile load - horizontal deformation curves of two bracing bracket connections (hereaf- ter, referred to as simply Column 1 and Column 2) are shown in Fig. (5). The measuring range of LVDTs used in the bracing connection Column 1 is not large enough, but this testing flaw is improved in the subsequent test of bracing connection Column 2. The ultimate tension strength of Column 1 and Column 2 tests is $5.65 \mathrm{kN}$ and $7.6 \mathrm{kN}$ respectively. As shown in Fig. (5), tensile load - deformation test curves are divided into three parts. The slope of first curve part is largest, and all components of bracing connection remain in the elastic condition. In the second curve part, some portion of column web occurs plastic deformation, resulting in a lower curve slope. The third curve part is close to the horizontal line, indicating that the destruction of column web is about to happen, and connecting bolts are coming to be pulled out from column web.

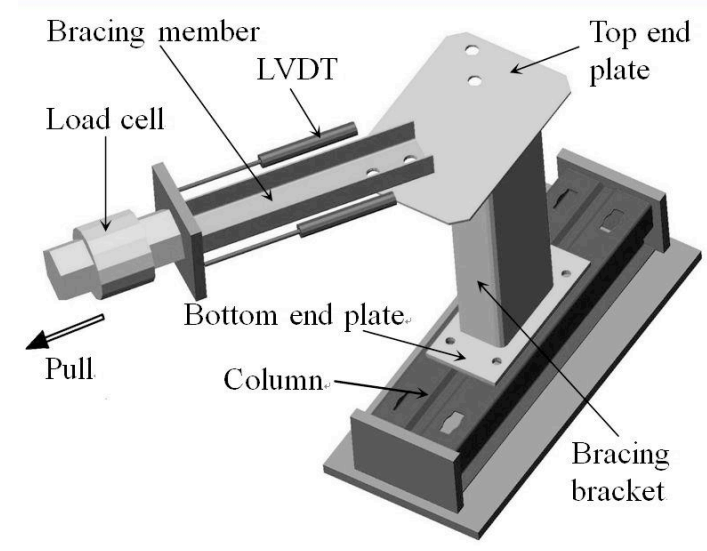

Fig. (3). Test arrangement of spine bracing connection in single entry racks.

Table 1. Material properties of connection components.

\begin{tabular}{|c|c|c|c|c|}
\hline Component & $\boldsymbol{t}(\mathbf{m m})$ & $\boldsymbol{f}_{\mathbf{y}}(\mathbf{M P a})$ & $\boldsymbol{f}_{\mathrm{u}}(\mathbf{M P a})$ & $\boldsymbol{E}\left(\mathbf{1 0} \mathbf{5}^{\mathbf{M}} \mathbf{M a}\right)$ \\
\hline \hline Column 1 & 1.75 & 289 & 384 & 2.0 \\
\hline Column 2 & 2.20 & 359 & 446 & 1.9 \\
\hline $\begin{array}{c}\text { Bracing } \\
\text { bracket }\end{array}$ & 2.95 & 303 & 411 & 2.0 \\
\hline
\end{tabular}
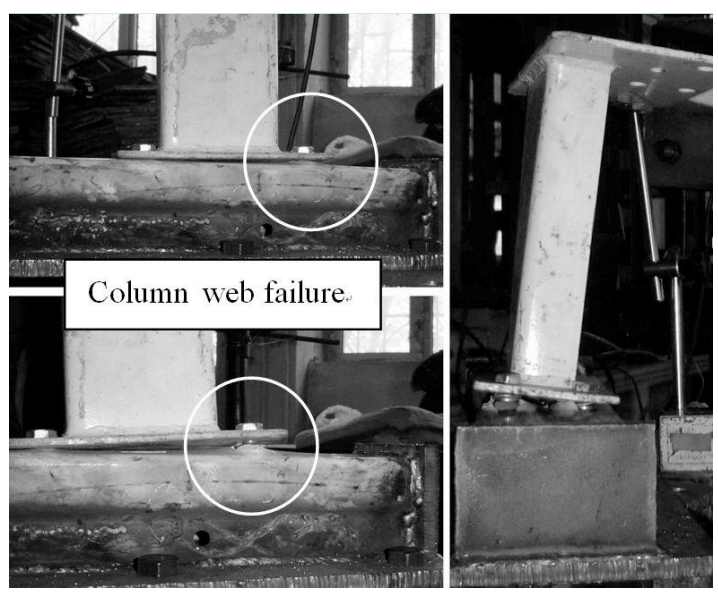

Fig. (4). Failure phenomena of bracing bracket connection. 


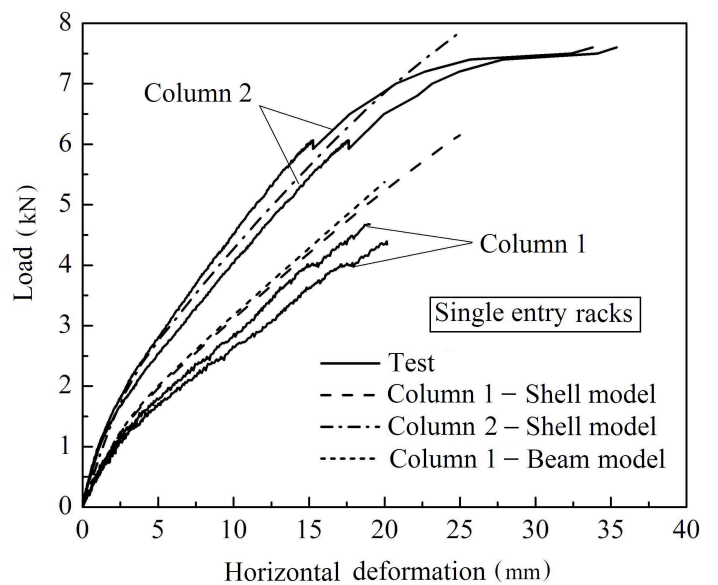

Fig. (5). Tensile load - horizontal deformation curves of bracing bracket connections.

\section{FINITE ELEMENT CALCULATION}

In the previous section, the only static tensile tests of bracing connection in single entry racks have been carried out, but the bracing connection in double entry racks is not tested. However, the establishment method of finite element models of bracing connection in single entry racks and double entry racks is similar. After minor improvements, the finite element model of bracing connection in single entry racks, which is validated by experimental results, can be used to examine the mechanical performance of bracing connection in double entry racks.

The finite element software ANSYS is used to simulate the experimental behavior of bracing connection in single entry racks. The short column, bracing bracket and its two end plates are modeled using the shell element SHELL181.

As shown in Fig. (3), in the finite element model, the treatment of connection between bottom end plate and column web plate is introduced as follows, the nodes of the two plates at the position of connecting bolt are coupled, and the nodes at other position of the two plates are linked using contact elements TARGE170 and CONTA174. Diagonal bracing members are modeled using the beam element BEAM1 88 with the custom cross section. In addition to the vertical bracing connection in single entry racks, the finite element model of bracing connection in double entry racks is also established using the similar method. Finite element analytical models of the two types of bracing connections are shown in Fig. (6).

After the numerical calculation, the tensile load - horizontal deformation curves of bracing connection in single entry racks are shown in Fig. (5). The calculated curves are in good agreement with experimental curves. Besides, the calculated tensile load - horizontal deformation curves of bracing connection in double entry racks are given in Fig. (7). Only one column thickness (Column 1) is used in this numerical calculation of connection in double entry racks. Furthermore, these finite element models of double entry racks are divided into two types (Model 1 and Model 2) according to the different boundary conditions. See Fig. (6), for both short columns of connection in Model 1, all the displacement in three directions of two column ends and two flanges, which are welded on steel plate in tests, is constrained. However, for both short columns in Model 2, only the displacement in $\mathrm{X}$ and $\mathrm{Z}$ directions of two column ends and two flanges is constrained, and the displacement in $\mathrm{Y}$ direction is not constrained. In actual double entry racks, the degree of column constraint in Y direction for bracing connection is between the constraints of Model 1 and Model 2. As shown in Fig. (7), the difference of load - deformation curves of Shell model 1 and Shell model 2 is quite modest in the initial load stage, but the difference becomes larger with the increase of the pull force.

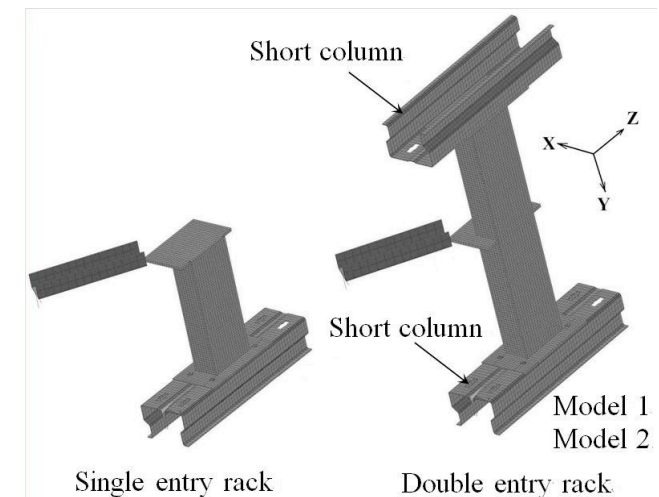

Fig. (6). Finite element models.

The comparison results of tensile secant stiffness of shell element models in single entry racks and double entry racks are list in Table 2 . The tensile stiffness of bracing connection in double entry racks is much larger than that of single entry racks. The mechanical behavior of bracing bracket in single entry racks is similar as a cantilever beam, but the mechanical behavior of bracing bracket in double entry racks is similar as a continuous beam. The cargo load of actual double entry racks is almost twice than that of single entry racks, but the numeral calculation results show that, the difference of lateral stiffness between single entry racks and double entry racks is much more than twice. The main reason for this large difference is that, the local deformation of bracing connection in double entry racks, especially the local deformation in column web, is remarkably less than that of single entry racks.

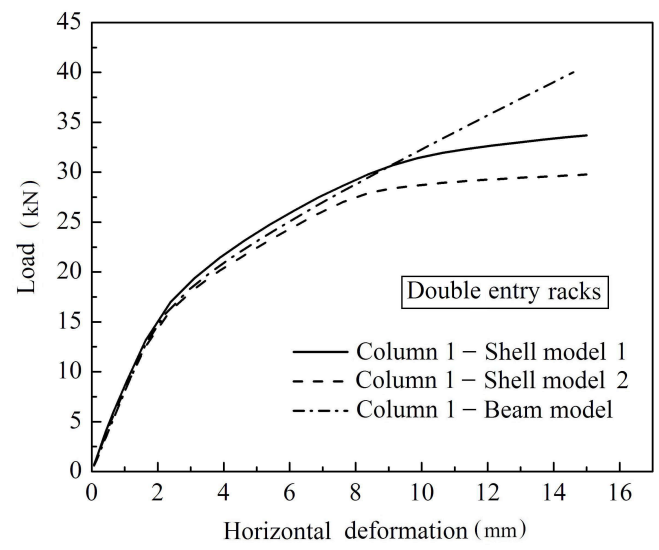

Fig. (7). Load- horizontal deformation curves of connections in double entry racks. 
Table 2. Stiffness of shell element models of column 1.

\begin{tabular}{|c|c|c|c|}
\hline \multirow{2}{*}{ Models } & \multicolumn{3}{|c|}{ Secant stiffness (kN/mm) } \\
\cline { 2 - 4 } & $\mathbf{2 m m}$ & $\mathbf{5 m m}$ & $\mathbf{8 m m}$ \\
\hline \hline Single entry rack model & 0.51 & 0.39 & 0.34 \\
\hline Double entry rack model 1 & 7.59 & 4.80 & 3.67 \\
\hline Double entry rack model 2 & 7.17 & 4.50 & 3.45 \\
\hline
\end{tabular}

The number of finite elements in shell element models mentioned above is large, and it takes a long time for the model building and calculating, thus the shell element model is not applicable in the numerical computation analysis of complete storage rack. In order to resolve this difficulty, bracing bracket is simplified into an elastic - plastic beam with the same length in this section, and the elastic - plastic beam is simulated by the finite beam element BEAM188. Specifically, the bracing bracket in single entry racks is simplified into a cantilever beam subjected to a concentrated force at the free end, but the bracing bracket in double entry racks is simplified into a continuous beam, which is rigidly fixed at both ends and is subjected to a concentrated force at mid-span. By changing geometrical dimensions, material properties (including elastic modulus and yield strength), the tensile load - horizontal deformation curves of simplified elastic - plastic beam element models can be well consistent with the calculated curves of shell element models (see Fig. 5 and Fig. 7).

Table 3. Section properties of high rack components.

\begin{tabular}{|c|c|c|c|}
\hline Members & Area $\left(\mathbf{m m}^{2}\right)$ & $\mathbf{I}_{\max }\left(\mathbf{m m}^{\mathbf{4}}\right)$ & $\mathbf{I}_{\mathbf{m i n}}\left(\mathbf{m m}^{\mathbf{4}}\right)$ \\
\hline \hline Column & $5 \times 10^{2}$ & $7.3 \times 10^{5}$ & $3 \times 10^{5}$ \\
\hline Beam & $6 \times 10^{2}$ & $9.5 \times 10^{5}$ & $2.4 \times 10^{5}$ \\
\hline Column bracing & $1.9 \times 10^{2}$ & & \\
\hline $\begin{array}{c}\text { Spine and plan } \\
\text { bracing }\end{array}$ & $2.2 \times 10^{2}$ & & \\
\hline
\end{tabular}

\section{LATERAL DEFORMATION OF HIGH RACK}

In order to analyze the impact of spine bracing systems on the lateral stiffness of high selective racks in the downaisle direction, complete finite element beam models of single entry racks and double entry racks are established and calculated in this section. The configuration of high storage racks are shown in Fig. (8). Furthermore, all dimensions in Fig. (8) are in millimeters. The studied racks have four bays. Each beam in one bay supports two pallets with stored goods. The vertical spine bracing system is only installed in one bay, and the horizontal plan bracing system is only installed at the top of rack. There are eight floors of goods pallets in the studied racks. Columns and beams are simulated by elastic beam element BEAM4, but all the bracing members (including column bracing, spine bracing and plan bracing) are simulated by elastic link element LINK8. The geometrical dimensions and material properties of simplified beam element model mentioned above are adopted for the geometric and material parameters of spine bracing bracket in the complete rack model to capture the characteristics of spine bracing. Section properties of rack components are listed in Table 3. According to the experimental research of flexural capacity of the beam - to - column connection in references [2] and [3], the bending stiffness of beam - to column connection in the complete rack model is determined as $80 \mathrm{kN} . \mathrm{m} / \mathrm{rad}$. Depending on the different geometric construction and column axial force in column base connection, the bending stiffness of column base connection can vary greatly $[4,5]$. The complete rack model in this section considers two simplified cases [6]: pinned base connection and rigid base connection.

The weight of each load unit is determined as $500 \mathrm{~kg}$ in the rack model, and this gravity load is uniformly distributed on the rack beam. For the horizontal load which is applied at the connection nodes of rack beam and column, there are two kinds of causing factors. One kind of causing factor is about different defects in racks, such as initial deformation of rack members, installation deviation, eccentric loading, and so on. The other kind of causing factor is horizontal earthquake action, and this horizontal load applied at rack is closely related to the natural vibration period of rack structure. Based on the above analysis, the horizontal load applied at rack in this section is selected as three percent of vertical gravity load of goods on pallets.

Lateral displacements of single entry racks and double entry racks under the action of horizontal load are shown in Fig. (9a) and Fig. (9b) respectively. Fig. (8) gives the specific location of lateral displacement measurement points, which are the intersection points of two middle columns and different floors of beams. In Fig. (9), rack PW means that the analyzed rack has pinned base connection but does not have a spine bracing system. Rack RW means that the analyzed rack has rigid base connection but does not have a spine bracing system. Rack PB means that the analyzed rack has pinned base connection and spine bracing system. Rack RB means the analyzed rack has rigid base connection and spine bracing system.

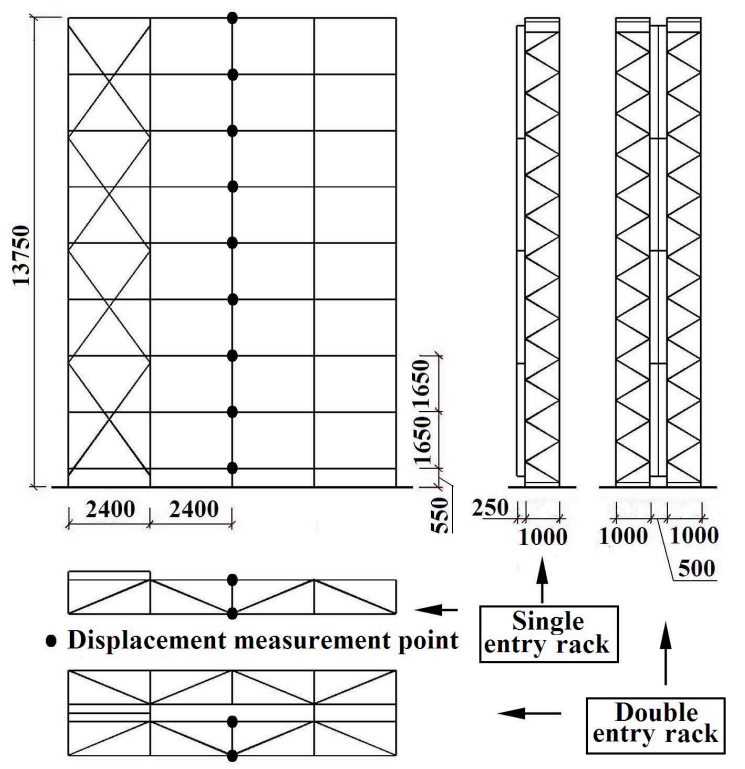

Fig. (8). Configuration of high storage racks studied in the paper. 


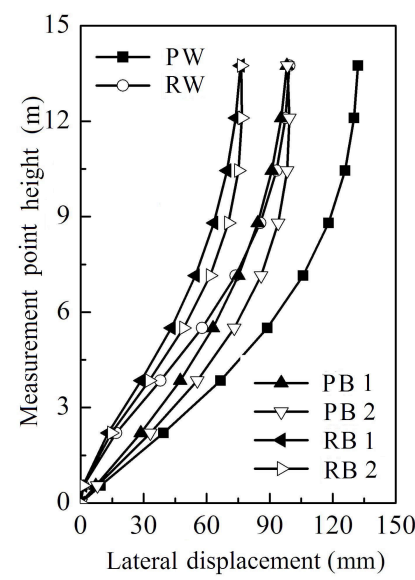

(a) Single entry rack

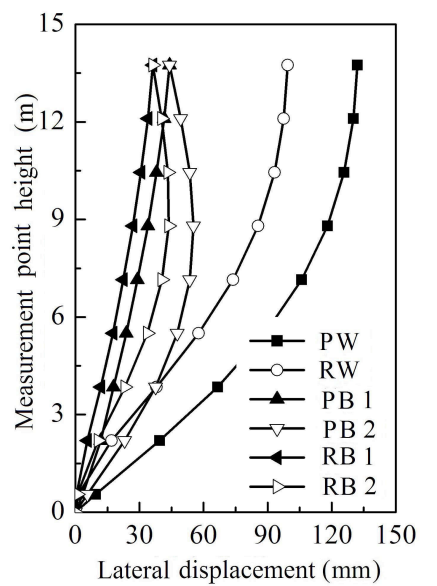

(b) Double entry rack
Fig. (9). Lateral displacement of racks.

For the analyzed racks without spine bracing, the lateral displacements of two measured columns are the same, so there is the displacement date of only one column for one analyzed rack in Fig. (9) (PW and RW). However, in the analyzed racks with spine bracing, because the horizontal plan bracing is only set at the top of rack, the lateral displacements of two measured columns are different. The deformation of inside measured column is small (PB1 and RB1), and the deformation of outside measured column is bigger (PB2 and RB2), especially at the middle of the column.

For the analyzed racks without spine bracings system, the lateral displacements of single entry racks and double entry racks are the same. However, the impacts of setting spine bracings on lateral displacements of single entry racks and double entry racks are different, the latter impact being large. For the single entry racks with pinned column base, spine bracings reduce the maximum horizontal displacement of racks from $132 \mathrm{~mm}$ to $99.3 \mathrm{~mm}$. For the single entry rack with rigid column base, spine bracings reduce the maximum horizontal displacement from $99.4 \mathrm{~mm}$ to $76.7 \mathrm{~mm}$. For the double entry racks with pinned column base, spine bracings reduce the maximum horizontal displacement from $132 \mathrm{~mm}$ to $55.2 \mathrm{~mm}$. For the double entry racks with rigid column base, spine bracings reduce the maximum horizontal displacement from $99.4 \mathrm{~mm}$ to $43.7 \mathrm{~mm}$.

Based on the numerical calculation, maximum tension forces of spine bracing members in single entry rack PB and rack $\mathrm{RB}$ are $3.4 \mathrm{kN}$ and $2.4 \mathrm{kN}$ respectively, and maximum tension forces of spine bracing members in double entry rack $\mathrm{PB}$ and rack $\mathrm{RB}$ are $17.7 \mathrm{kN}$ and $14.1 \mathrm{kN}$ respectively. The maximum tension forces of bracing members mentioned above are smaller than the ultimate tensile bearing capacity of bracing connections (see Fig. 5 and Fig. 7). The maximum axial force of bracing members in double entry racks is significantly greater than that of single entry racks. This contrasting result also suggests that the spine bracing members play a greater role in double entry racks.

\section{CONCLUSION}

This paper mainly discusses the shear stiffness of spine bracing systems in selective storage racks, and contains three parts of research content, destructive tests of bracing bracket connection, numerical simulation of tested bracing connections and numerical calculation of complete high storage rack.

Only the spine bracing bracket connections in single entry racks are studied experimentally. The main failure phenomena of tested bracing connections are that, the portion of column web around bolt holes is torn and the connecting bolts are pulled out from column web. Experimental results indicate that, in the vertical spine bracing system of racks, the local deformation of bracing connection is larger than that of bracing member, and meanwhile the bearing capacity of bracing connection is less than that of bracing member.

The numerical research of spine bracing connections shows that the load passing way of spine bracing bracket in double entry racks is more reasonable than that of single entry racks, so the local deformation of bracing bracket in double entry racks is relatively small, resulting in a much better mechanical performance of spine bracing systems in double entry racks.

In the situation that the structural parameters of two types of racks are exactly the same, the maximum lateral displacement of double entry racks with spine bracings is less than that of single entry racks by about $40 \%$, showing the large difference of lateral stiffness between these two types of selective racks in the down-aisle direction. The situation above is not embodied in the present rack design specifications and rack design procedure, thus the spine bracing systems in single entry racks needs to be suitably reinforced to get the equivalent stability with double entry racks.

\section{ABOUT THE AUTHORS}

First Author Bo Cheng, master degree in engineering, studying for $\mathrm{PhD}$ in Harbin Institute of Technology of Civil Engineering. The author's major is Structural Engineering.

Second Author Zhenyu Wu, University professor of Harbin Institute of Technology, PhD. The author's major is light steel structure and high-rise steel structure.

\section{CONFLICT OF INTEREST}

The authors confirm that this article content has no conflict of interest.

\section{ACKNOWLEDGEMENTS}

This work was financially supported by the China National Natural Science Foundation (50978076).

\section{REFERENCES}

[1] EN 15512, Steel static storage systems - Adjustable pallet racking systems - Principles for structural design, European Committee for Standardization (CEN), Brussels, Belgium, 2009. 
[2] F. D. Markazi, R. G. Beale, and M. H. R. Godley, "Experimental analysis of semi-rigid boltless connectors", Thin-Walled Structures, vol. 28, pp. 57-87, 1997.

[3] P. Prabha, V. Marimuthu, and M. Saravanan, "Evaluation of connection flexibility in cold formed steel racks", Journal of Constructional Steel Research, vol. 66, pp. 863-872, 2010.

[4] J. J. C. Diaz, P. J. G. Nieto, and C. B. Biempica, "Non-linear analysis of unbolted base plates by the FEM and experimental validation", Thin-Walled Structures, vol. 44, pp. 529-541, 2006.
[5] B. P. Gilbert, and K. J. R. Rasmussen, "Determination of the base plate stiffness and strength of steel storage racks", Journal of Constructional of Steel Research, vol. 67, pp. 1031-1041, 2011.

[6] N. Baldassino, and C. Bernuzzi. "Analysis and behaviour of steel storage pallet racks", Thin-Walled Structures, vol. 37, pp. 277-304, 2000 .

Received: January 25, 2015

Revised: March 01, 2015

Accepted: March 10, 2015

(C) Cheng and Wu; Licensee Bentham Open.

This is an open access article licensed under the terms of the Creative Commons Attribution Non-Commercial License (http://creativecommons.org/licenses/by-nc/4.0/) which permits unrestricted, non-commercial use, distribution and reproduction in any medium, provided the work is properly cited. 